\title{
On the Shear Behavior of Engineered Cementitious Composites
}

\author{
Victor C. Li, Dhanada K. Mishra, Antoine E. Naaman, James K. Wight, \\ James M. LaFave, Hwai-Chung Wu, and Yasou Inada \\ Department of Civil and Environmental Engineering, University of Michigan, Ann Arbor, \\ Michigan; and Institute of Technology, Shimizu Corporation, Tokyo, Japan
}

Results of an experimental investigation of structural response of shear beams made of a special class of cementitious composites, referred to as engineered cementitious composites (ECCs), are reported. ECCs are designed with tailored material structure and have been shown to exhibit pseudo strain-hardening tensile behavior. The improved performance in shear over conventional plain, fiberreinforced, and wire mesh reinforced concrete is demonstrated. It is suggested that ECCs can be utilized for structural applications where superior ductility and durability performance are desired. Advanced Cement Based Materlals 1993, 1, 142-149

KEY WORDS: Cementitious composite, Ductility, Engineered cementitious composites, Ohno shear beam, Shear, Structural performance.

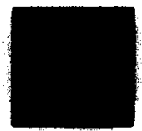

ngineered cementitious composites (ECCs) belong to a class of short, random, fiberreinforced, cement based materials with designed microstructures such that the composite undergoes pseudo strain-hardening, instead of softening, when the first crack strain is exceeded. As a result, ECCs are characterized by ultimate tensile strain and fracture energies, which can be as much as two orders of magnitude higher than conventional cementitious materials [1-3]. ECCs can be designed with different fiber types and can be processed by regular mixing and casting techniques. In some cases, ECCs can be made with as little as 1 vol.\% fiber. The unique properties of ECCs can be exploited in structural applications demanding high ductility and energy absorption, such as in connections in earthquake-resistant structures, or in applications demanding crack width control and longterm durability such as bridge decks and pavements.

\section{Failure in Shear}

In this article, the focus is specifically on structural performance in response to intense shear loading.

Address correspondence to: Victor C. Li, Professor of Civil and Environmental Engineering, 2326 G.G. Brown Building, The University of Michigan, Ann Arbor, MI 48109-2125.
Shear failure is generally brittle in concrete structures. Examples of concrete structural failure related to shear loading include bridge deck punching failure [4], corbel failure [5], anchor bolt pull-out [6], and segmental bridge shear key failure [7]. A goal of the work presented here is to modify the brittle failure mode by taking advantage of the unique material behavior of ECCs. There has been a lot of research into the use of fibers as a replacement for shear reinforcement to enhance shear capacity of concrete beams to ensure a ductile final failure in flexure in reinforced concrete beams [8-13]. Most of this research emphasized testing of conventional reinforced beams to study the effects of shear span to effective depth ratio, fiber type, volume fraction and aspect ratio, and longitudinal steel content, on the shear capacity. The analytical formulation is generally based on parametric studies to predict shear strength, which is assumed to be composed of contributions from fiber pull-out, aggregate interlock, dowel action of rebars, etc. The material used in these programs is ordinary fiber-reinforced concrete, which does not exhibit pseudo strain-hardening.

Study of shear behavior in high fiber volume fraction ( 8 to $12 \%$ ) slurry-infiltrated fiber concrete (SIFCON) was reported in refs $13-15$. While significant improvements in strength and ductility were found, refs 15 and 16 also reported highly anisotropic effects due to fiber orientation associated with the processing method of SIFCON. Failure on weak planes parallel to the fiber bedding direction was observed. The ECCs studied in this program use a normal mixing process and no anisotropic effect or weak planes can be identified.

\section{Research Significance}

This study is primarily concerned with the translation of pseudo strain-hardening properties of ECC materials from the materials level to the structural level. This investigation is based on the concept of the performance driven design approach [17] depicted in Figure 1. This approach aims at material structure design 


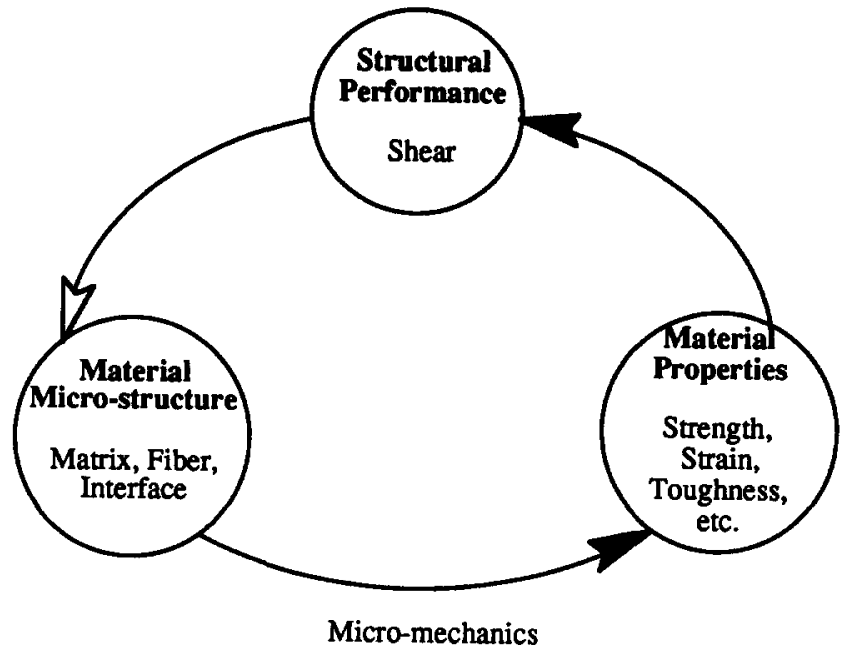

FIGURE 1. The performance driven design approach for shear intensive structural applications.

based on structural performance requirements. For this novel approach to materials design to succeed, the linkage between the structural performance requirement and composite properties, and the linkage of the latter with microstructural parameters, must be quantitatively established. Such an attempt is made in this study with respect to structural shear performance. Also, advantage has been taken for the first time of the ideas of micromechanics based materials design for improved shear performance.

\section{Experimental Program}

The experimental results reported in this article are part of an ongoing research program to establish the link between shear behavior on a structural component level and the composite properties such as tensile strength, strain capacity, and fracture energy determined on a materials level. The argument is made that structural shear failure is basically tensile failure at a local level. Hence, improvement of tensile properties of the cementitious composite should directly influence shear structural performance. The major objective of this experimental program is to establish the shear performance of ECCs, and contrast it with plain concrete, conventionally reinforced concrete, and ordinary fiber-reinforced concrete.

\section{Specimen Design}

The Ohno shear beam configuration [18] (shown in Figure 2) was chosen for this testing program. The geometry and loading arrangements are also indicated in Figure 2. As can be observed from the accompanying shear force and bending moment diagrams (Figure
3), a state of pure shear exists at the center of the shear panel where the bending moment is zero. The flexural steel has been designed to prevent flexural failure in the shear panel and ensure a shear mode of failure. The flexural reinforcement layout is shown schematically in Figure 2. The amount and position of the \#3 bars were calculated by considering clear cover requirement, adequate bar development length, and maximum flexural stress at failure of the beam. The tips of the bars were tapered to reduce stress concentration. Further details can be found in ref 19 . Since a state of pure shear stress exists at the centroid of the specimen, the Ohno shear specimen gives an estimate of shear strength that is closer to the actual shear strength of the material (as would be obtained in a biaxial tension-compression test) as compared with the conventional two-point loading shear beam test.

\section{Materials Design and Processing}

Four different mixes were used in this test program. The mix proportions, by dry weight, of the components for the four mixes are shown in Table 1. The designations used to identify different mixes are as follows: PC for plain concrete, FRC for plain concrete with $1 \%$ by volume of ZL $30 / 50$ fibers ( $30-\mathrm{mm}$ long and $0.5-\mathrm{mm}$ diameter steel fibers with hooked ends), DRECC for ECC mix with $7 \%$ by volume Dramix fibers

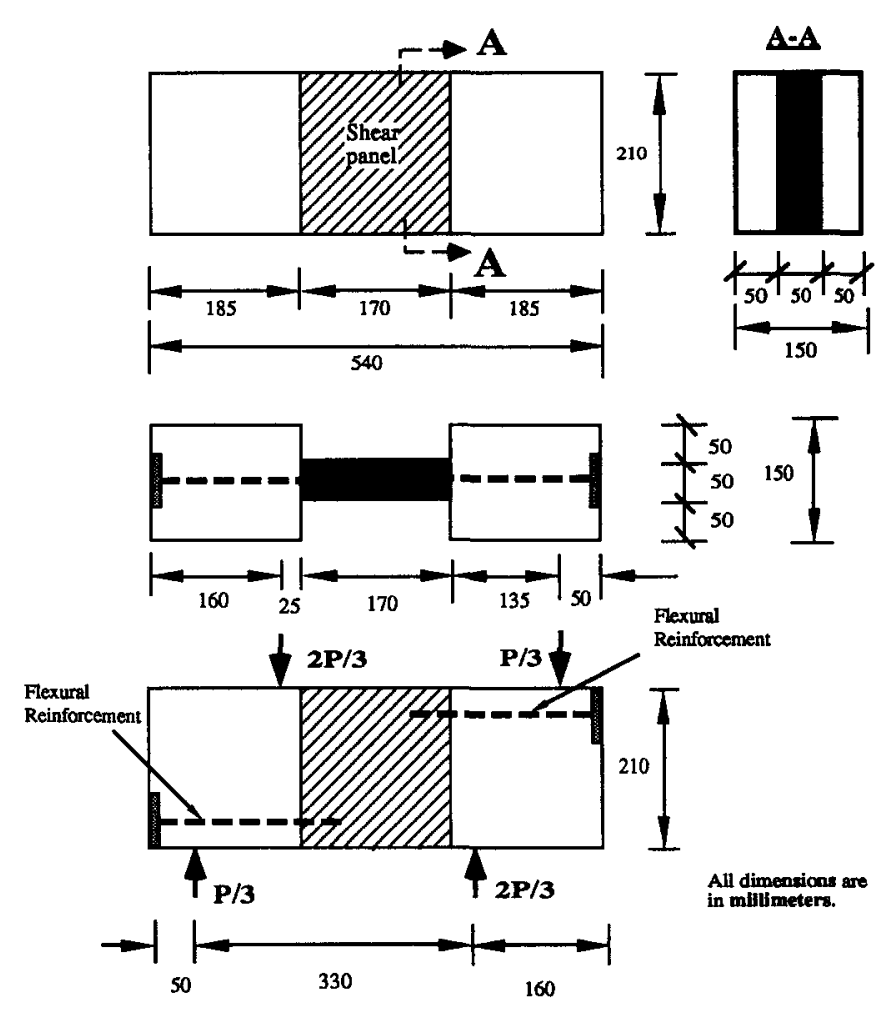

FIGURE 2. Ohno shear beam specimen geometry and dimensions. 

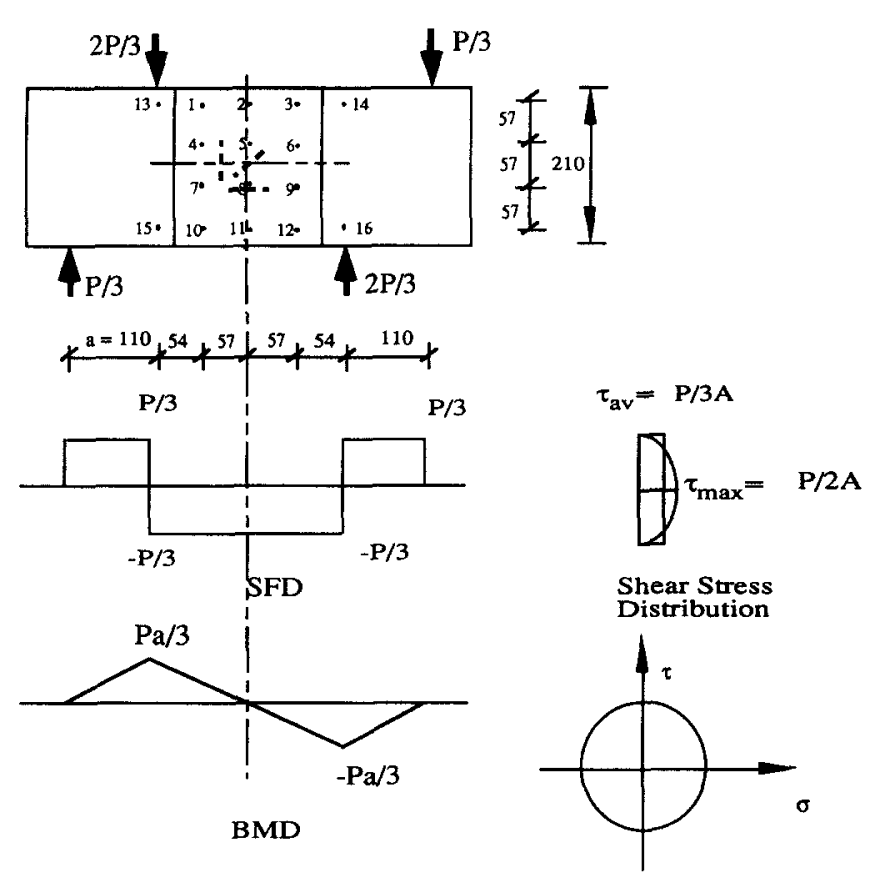

Mohr's Circle for Pure Shear

OPTOTRAK targets

. Strain Gage

All dimensions are
in millimeters.

FIGURE 3. Instrumentation and shear force and bending moment diagrams.

(6-mm long and 0.15-mm diameter, brass-coated steel fibers), and SPECC for ECC mix with $2 \%$ by volume Spectra fibers (12.7-mm long and 0.038-mm diameter polyethylene fibers). The DRECC provides high tensile strength and moderate tensile ductility, while the SPECC provides moderate strength and high ductility. The PC beam was used to establish a reference point. The FRC represents typical commercially used fiberreinforced concrete materials. For the purpose of comparison, one of the PC beam specimens was reinforced with conventional shear reinforcement (RC) in the form of welded wire fabric $(25 \times 25-\mathrm{mm}$ square grid of $3.5-\mathrm{mm}$ diameter wires) in accordance with the $\mathrm{ACI}$ building code. The wire reinforcement provides a reinforcement ratio of about $0.75 \%$ in both the horizontal and vertical directions.

The PC and FRC material mixing was performed in a standard laboratory concrete mixer. Both ECC materials were mixed in a three-speed laboratory mixer with a planetary rotating blade. Specimens were mixed and cast per relevant provisions of ASTM C192. For each batch of material, one Ohno shear beam, three $76 \times$ $152 \mathrm{~mm}$ compression cylinders, three $76 \times 13 \times 305$ $\mathrm{mm}$ tension specimens, and three $152 \times 152 \times 35 \mathrm{~mm}$ compact tension specimens were cast. All specimens were moist cured for 24 hours before demolding, and subsequently cured in water for 4 weeks. The age at testing of all specimens was 5 to 6 weeks. Details of the processing of the ECCs are described in ref 20.

\section{Test Set-up}

The Ohno shear beams were tested in an Instron model 8000 test system with a $500 \mathrm{kN}$ capacity loading frame. The tests were run under displacement control at a loading rate of $0.381 \mathrm{~mm} / \mathrm{min}$. Total test time was approximately 10 minutes. The loads were applied through rollers resting on 25.4 -mm wide thin aluminum spreader plates glued to the specimen, and the beams were placed on roller supports.

The main noncontacting deformation measurement unit was an OPTOTRAK three-dimensional digitizing and motion analysis system. This system consists of two infrared camera units which continuously monitor the positions of infrared emitting diodes (targets) attached to the specimen. An IBM PC-AT recorded the information. A total of 16 OPTOTRAK targets were utilized during the shear tests. The locations of the grid of OPTOTRAK targets used are shown in Figure 3. An auxiliary surface bonded strain gauge rosette was used to determine precracking deformation in the region of pure shear near the center of the specimen as shown in Figure 3 . In some specimens a pair of strain gauges were aligned parallel to the maximum principal tensile stress (diagonal) direction.

TABLE 1. Material mix designation and proportions

\begin{tabular}{|c|c|c|c|c|c|}
\hline $\begin{array}{l}\text { Mix } \\
\text { designation }\end{array}$ & Cement & Aggregates & W/C & Additives & $\begin{array}{c}\text { Fibers } \\
\text { (by volume) }\end{array}$ \\
\hline $\begin{array}{l}\text { PC } \\
\text { FRC }\end{array}$ & $\begin{array}{l}1 \\
1\end{array}$ & $\begin{array}{l}\text { CA:FA }=1.72: 1.72 \\
\text { CA:FA }=1.72: 1.72\end{array}$ & $\begin{array}{l}0.45 \\
0.45\end{array}$ & $\begin{array}{l}\text { None } \\
\text { None }\end{array}$ & $\begin{array}{c}\text { None } \\
\text { ZL30/50 } \\
V_{f}=1 \%\end{array}$ \\
\hline SPECC & 1 & None & 0.27 & $\begin{array}{l}\mathrm{SF}=0.20 \\
\mathrm{SP}=0.03\end{array}$ & $\begin{array}{c}\text { Spectra } \\
V_{f}=2 \%\end{array}$ \\
\hline DRECC & 1 & None & 0.27 & $\begin{array}{c}\mathrm{SF}=0.20 \\
\mathrm{CpAg}=0.25 \% \\
\mathrm{SP}=0.03\end{array}$ & $\begin{array}{c}\text { Dramix } \\
\mathrm{V}_{\mathrm{f}}=7 \%\end{array}$ \\
\hline
\end{tabular}

CA, coarse aggregate; FA, fine aggregate; $W$, water; $S F$, silica fume; $\mathrm{CpAg}$, coupling agent; SP, super-plasticizer. 


\section{Test Results and Discussion}

\section{Basic Material Properties}

The experimental results may be categorized as shear beam test results and material test results. The material compressive strength (measured from standard cylinder tests), tensile strength (measured from direct tension tests of plate specimens), and fracture toughness (measured from compact tension specimens) are listed in Table 2. Details of the material properties and testing procedures of the ECCs are reported elsewhere $[19,20]$. The material tests performed in this program are used to form a baseline reference for interpreting the Ohno shear beam test results.

The material test results are the average of at least three tests, except in the case of the fracture test of SPECC, in which only two tests were conducted due to large specimen size requirements [2]. It should be noted that, in terms of the compressive strength, the different material systems show comparable performance except for the DRECC system, which has about twice the compressive strength of the others. The tensile strengths of both ECC systems are superior to those of the PC and FRC systems. The strain capacity and fracture toughness of both ECC mixes show orders of magnitude difference from that of PC. Figure 4, for example, shows a comparison of the tensile stressstrain relationships for the various cementitious materials tested in this program. Whether the advantageous trends in composite properties of the ECCs translate into improved shear performance of the Ohno beams will be addressed below.

\section{Shear Strength}

Results from the testing of five Ohno shear beams are plotted in the form of average shear stress versus average shear strain in Figure 5. Further shear test results are tabulated in Table 3. The average shear strength in the Ohno shear beams was estimated as the shear force at the beam center line (which is one-third of the ram load; Figure 3) divided by the cross-sectional area resisting the shear force. Comparisons of the shear strength at first crack and at ultimate load for the five

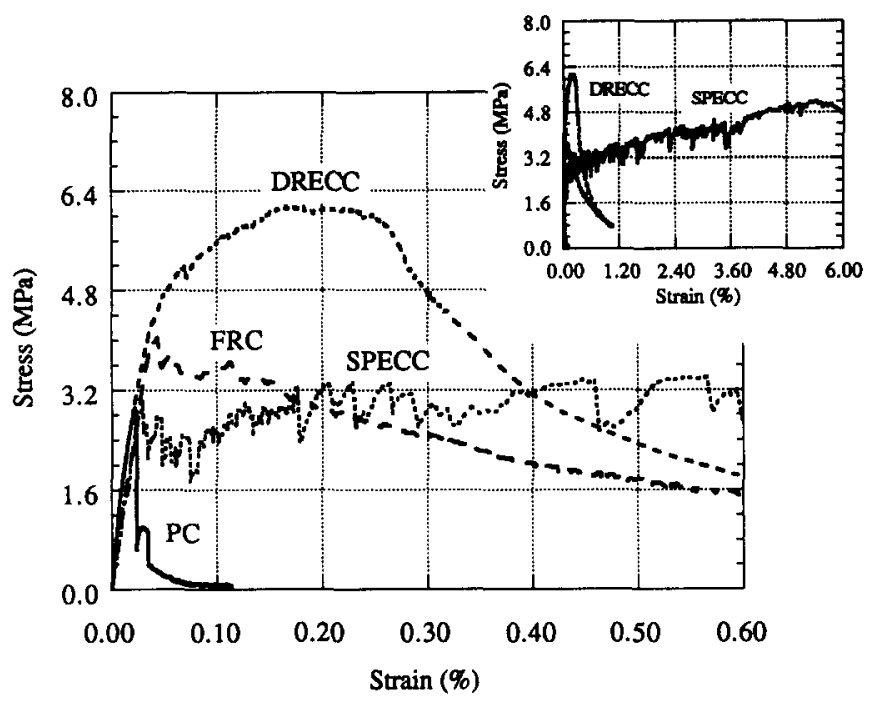

FIGURE 4. Uniaxial tensile stress-strain curves for PC, FRC, and the ECCs.

Ohno beams are shown in Figure 6. It can be observed that in spite of having no conventional shear reinforcement, the two ECC systems performed very well in comparison with the PC, RC, and FRC systems. The DRECC designed for high strength and moderate ductility failed at an ultimate shear stress of $9.89 \mathrm{MPa}$, which was about $300 \%$ more than the PC and about $81 \%$ higher than the RC system. The increase over the FRC systems was $226 \%$. On the other hand, the SPECC system that was designed for high strain capacity and only moderate load carrying capacity failed at a stress of $5.09 \mathrm{MPa}$, which was about twice that of the PC system and only slightly lower (about 7\%) than the $\mathrm{RC}$ specimen.

\section{Shear Strain}

The linear strains were calculated using the OPTOTRAK data, along the horizontal $\left(\epsilon_{1}\right)$, vertical $\left(\epsilon_{2}\right)$, and diagonal directions $\left(\epsilon_{3}\right)$ of a square formed by four OPTOTRAK targets (Figure 3). The engineering shear strain was then calculated using strain transformation laws, resulting in

$$
\gamma_{a v}=2 \epsilon_{3}-\epsilon_{1}-\epsilon_{2} \text {. }
$$

TABLE 2. Summary of material test results

\begin{tabular}{lcccc}
\hline Material & $\begin{array}{c}\text { Compressive } \\
\text { strength (MPa) }\end{array}$ & $\begin{array}{c}\text { Ultimate tensile } \\
\text { strength (MPa) }\end{array}$ & $\begin{array}{c}\text { Ultimate tensile } \\
\text { strain } \mathbf{( \% )}\end{array}$ & $\begin{array}{c}\text { Fracture toughness } \\
\left(\mathbf{k J / \mathbf { m } ^ { 2 } )}\right.\end{array}$ \\
\hline PC* & 41.8 & 2.5 & 0.02 & 0.13 \\
FRC & 47.9 & 4.3 & 0.05 & 4.85 \\
SPECC & 53.5 & 4.7 & 5.6 & 26.17 \\
DRECC & 89.2 & 6.2 & 0.15 & 3.85 \\
\hline
\end{tabular}

"Used for the concrete in RC. 


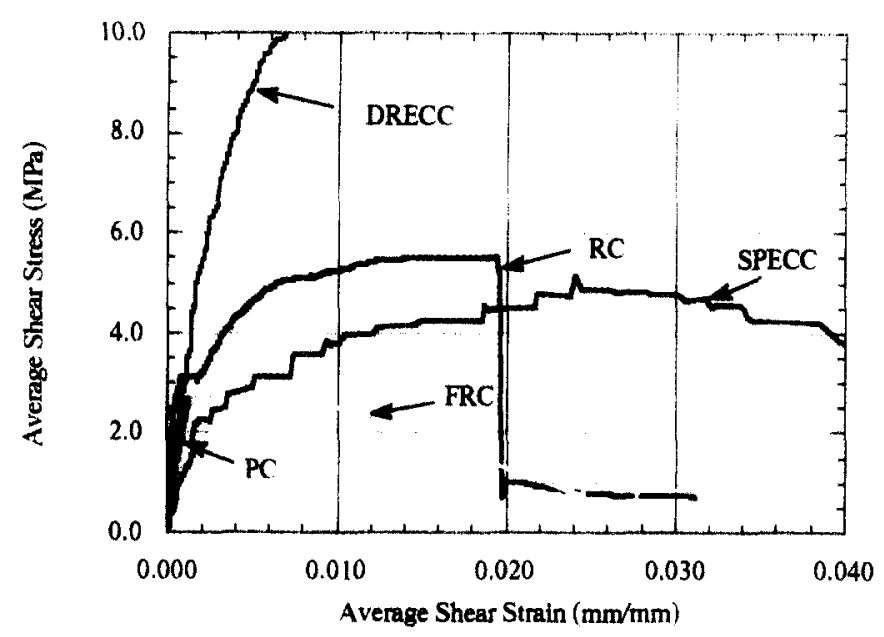

FIGURE 5. Average shear stress versus shear strain from readings of OPTOTRAK target movements on the shear panel.

Average values of the strains so measured are taken from two sets of four OPTOTRAK targets (1-3-9-7 and 4-6-12-10). In Table 3, the ultimate shear strain has been calculated at peak load. Comparisons of strain capacities for the five Ohno beams are shown in Figure 7. The strain at first crack for all systems is comparable, at about $0.1 \%$. However, the ultimate strain capacities are decidedly different. It can be observed that the first crack and ultimate strain capacity of the PC are about the same, around $0.1 \%$, suggesting immediate failure after the first crack. The conventional FRC system improves the strain capacity up to $0.6 \%$ due to the fiberbridging effect on cracks. This strain probably reflects the large crack opening which rapidly develops after the first crack and is therefore not a true strain. The RC system records a strain of $1.95 \%$ at the peak which is due almost entirely to the opening of one or two large cracks in the concrete and plastic deformation of the wire mesh crossing them. (The strains measured for the FRC and the RC systems after first crack strength reflect crack openings divided by the gauge length of the OPTOTRAK targets.) Unfortunately, it was not possible to capture the postpeak behavior of the DRECC system due to the low stiffness of the machine used in this test and the high failure load leading to an

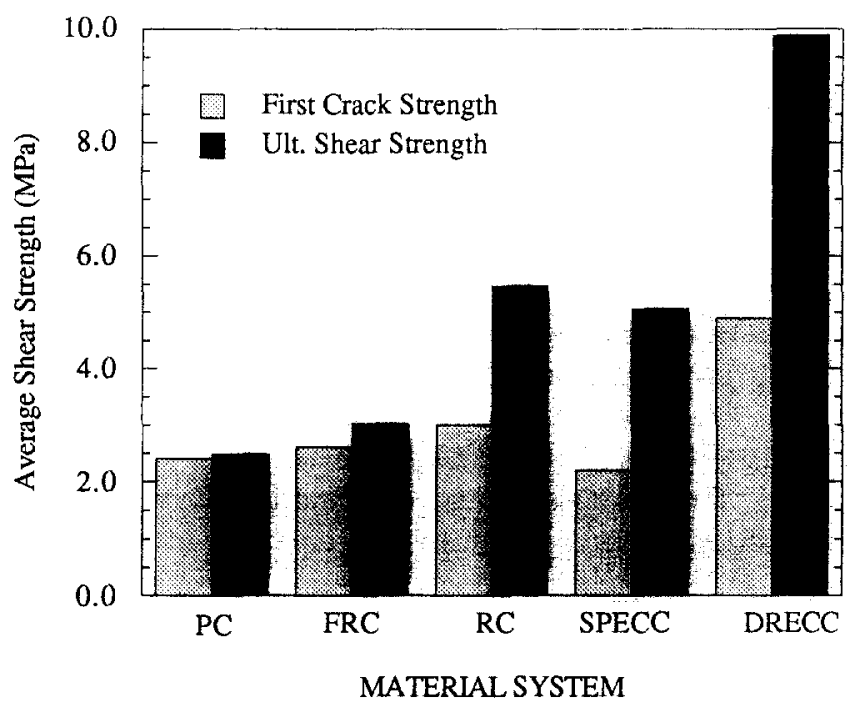

FIGURE 6. Comparison of the first crack and ultimate shear strengths of the various material systems.

unstable failure. However, the peak strain was still about $0.7 \%$, which is six times that of the PC system. The SPECC system showed the most ductile behavior as designed, and resulted in a peak strain of about $2.6 \%$, which is over 20 times the failure strain of PC. In both ECCs, no large cracks developed, so that the measured deformations were real strain due to distributed microcracking. This means that the energy absorption capacity of such a system would be significantly higher than that of ordinary cementitious materials and hence may prove ideal for applications in seismic-resistant structures and structures subjected to cyclic loading.

Theoretically, it is possible to correlate average shear strain, as measured above, with the direct tensile strain of the material using the Mohr's circle for strains in pure shear, from which the engineering shear strain at failure should be equal to twice the tensile strain capacity of the material. However, the OPTOTRAK target sets are offset from the center of the shear plane so that the stress state deviates from that of pure shear. In addition, the presence of tensile cracks emanating from the ends of the flexural rebars prior to peak load further contaminates the strain measurements.

TABLE 3. Summary of the Ohno shear beam test results

\begin{tabular}{lcccccc}
\hline Material & $\begin{array}{c}\text { First crack } \\
\text { strength (MPa) }\end{array}$ & $\begin{array}{c}\text { First crack } \\
\text { strain (\%) }\end{array}$ & $\begin{array}{c}\text { Visible crack } \\
\text { strength (MPa) }\end{array}$ & $\begin{array}{c}\text { Visible crack } \\
\text { strain (\%) }\end{array}$ & $\begin{array}{c}\text { Ultimate strength } \\
\text { (MPa) }\end{array}$ & $\begin{array}{c}\text { Ultimate strain } \\
(\%)\end{array}$ \\
\hline PC & 2.4 & 0.09 & 2.48 & 0.10 & 2.48 & 0.12 \\
RC & 3.0 & 0.11 & 3.12 & 0.125 & 5.47 & 1.95 \\
FRC & 2.6 & 0.12 & 2.83 & 0.20 & 3.03 & 0.6 \\
SPECC & 2.2 & 0.16 & 2.74 & 0.53 & 5.09 & 2.6 \\
DRECC & 4.9 & 0.17 & 9.70 & 0.62 & 9.89 & 0.7 \\
\hline
\end{tabular}




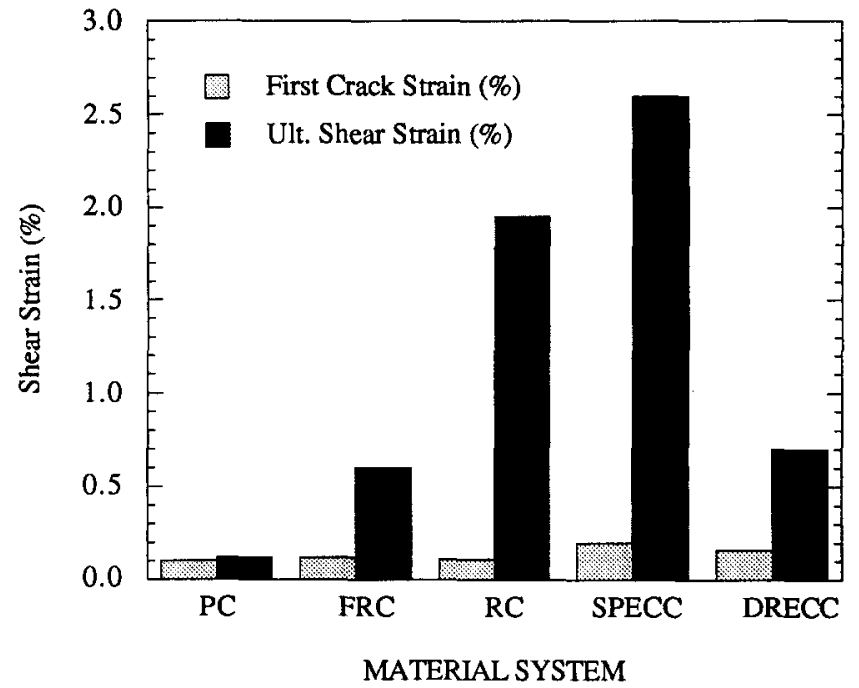

FIGURE 7. Comparison of shear strain capacities of different material systems. The ultimate shear strain for FRC and RC is composed primarily of large crack opening displacements.
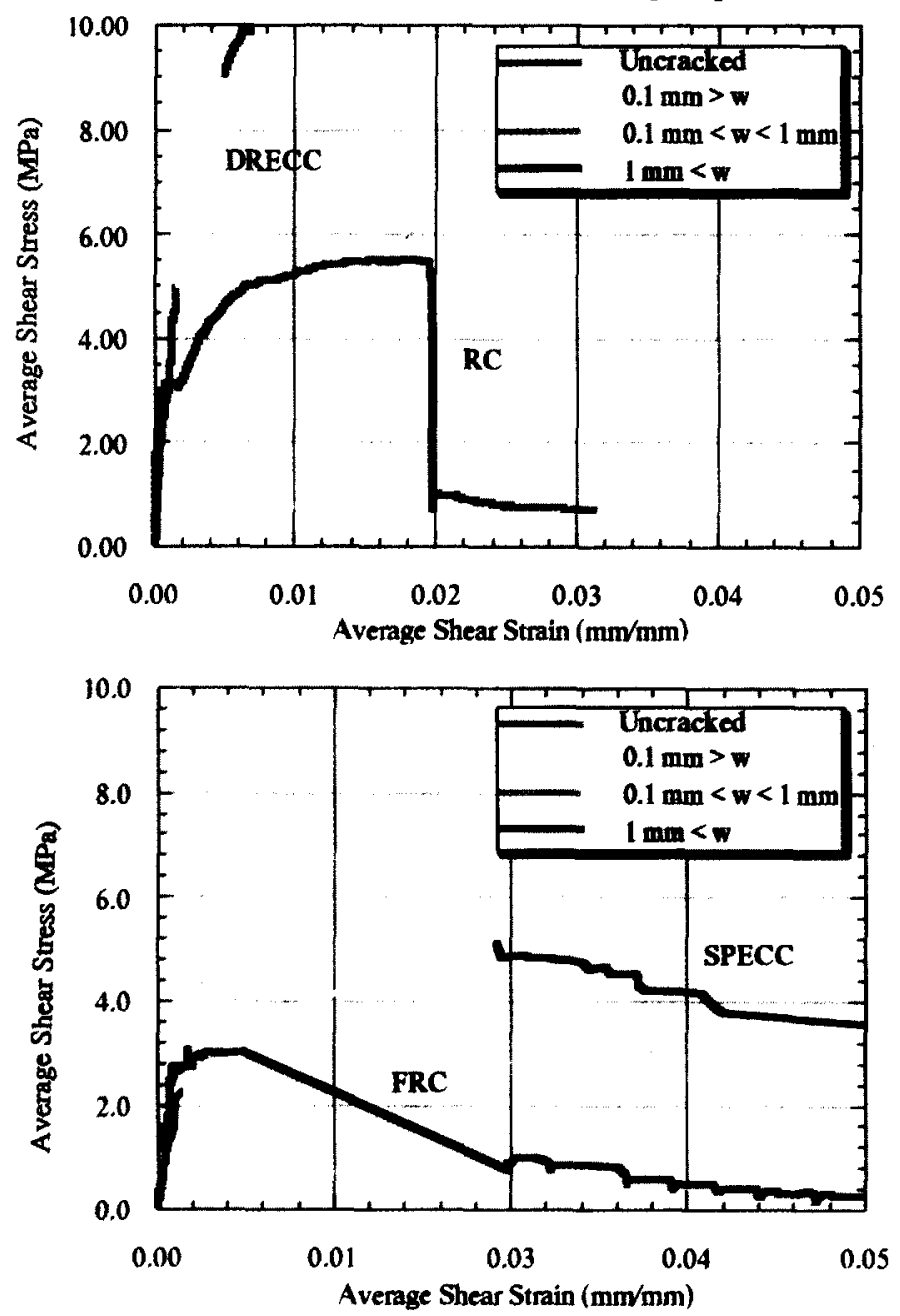

FIGURE 8. Cracking behavior of the different material systems. Color coding indicates crack widths at different loading stages.

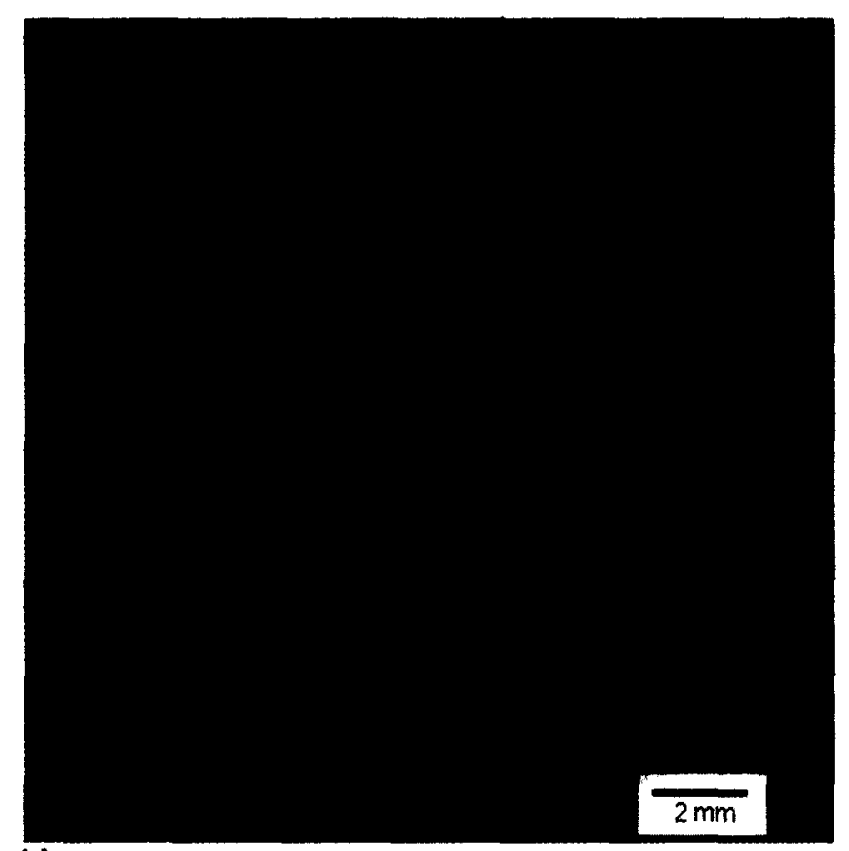

(a)

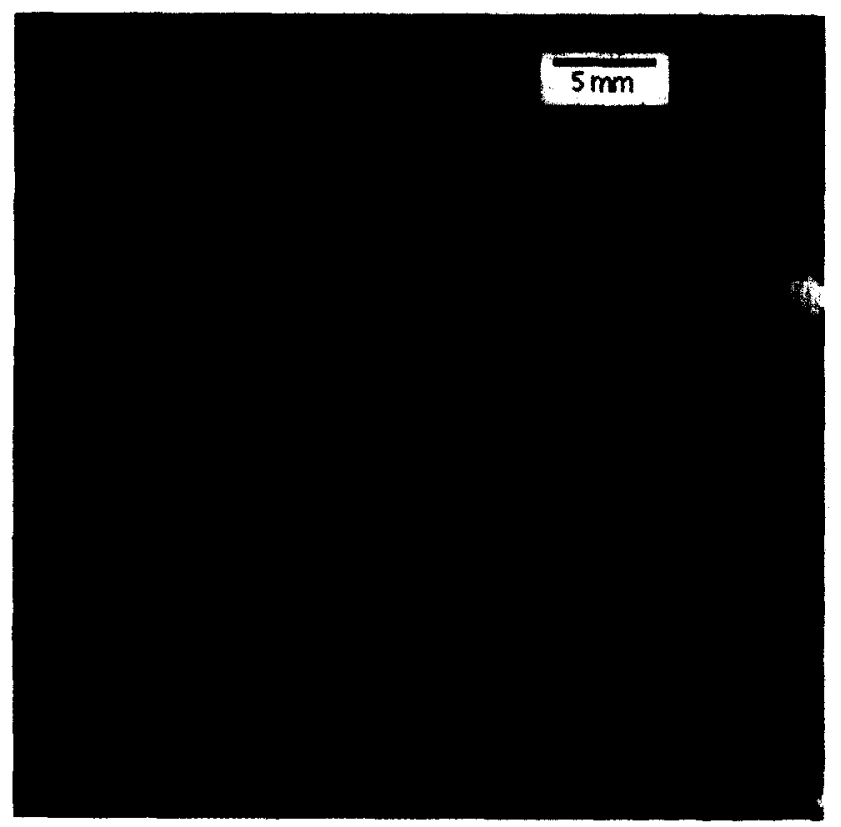

(b)

FIGURE 9. (a) Computer enhanced image of SPECC shear panel showing multiple cracking on the OPTOTRAK target side (with light ring of OPTOTRAK target on left side of photograph). (b). Computer enhanced image of SPECC shear panel showing multiple cracking on strain-gauged side (on upper left and lower right of photograph).

\section{Cracking Behavior}

Crack development of cement based materials is of major importance from the point of view of the durability and serviceability of a structure. One of the important 
findings of the current investigation was the enhanced cracking behavior of the ECC materials as compared with conventional cementitious materials in terms of the number of cracks and the crack widths. The cracking behaviors of the different specimens are depicted in Figure $8 a$ and $b$. The stress-strain behavior of each of the specimens has been divided into four regimes according to the approximate average crack widths observed during testing. The PC specimen has been omitted, as it fails immediately at first crack. In the case of the RC specimen, visible cracking occurs at a load level approximately equal to the failure load of the PC specimen, and immediately two large diagonal cracks are formed and crack widths jump into the third range $(0.1$ to $1 \mathrm{~mm})$. At the peak load, a third large crack forms suddenly due to failure of the bond between the steel shear reinforcement and the concrete. Large pieces of concrete spall can be observed. Shortly after the formation of the first crack, the specimen has such large cracks and exposed wire mesh that it is practically unusable from a serviceability point of view. The FRC specimen carried some load beyond the first crack load, and again a large diagonal crack formed as the load-carrying capacity dropped dramatically as shown in Figure 8b. In this case, the crack widths also suddenly jumped from the uncracked range to the third range. The cracking of the ECC specimens showed a fundamentally different behavior as compared to the other materials. The most important observation was the presence of a stage following first cracking where the crack widths were smaller than $0.1 \mathrm{~mm}$. In this region, due to multiple cracking, a large number of small cracks were formed rather than one or two big cracks. The multiple cracking of the SPECC specimen was clearly visible to the naked eye, as shown in the photograph in Figure 9. In the case of the DRECC specimen, the crack widths were not detectable by the naked eye, so they can only be inferred indirectly from strain gauge measurements of surface deformations, as shown in Figure 10. Multiple cracking was suggested by the increase in shear compliance after the first crack strength. The significant reduction in crack widths in the ECCs can translate directly into long-term gains in durability because the structure remains less permeable to harmful external agents.

\section{Biaxial Effect}

It is known that under biaxial tension-compression loading, concrete tends to exhibit softening characteristics, resulting in lower tensile strength and peak strain as compared to the uniaxial tensile case [21]. This phenomenon has not been established for FRC under direct biaxial loading. From the shear test results obtained in this study, one can infer the biaxial ten-

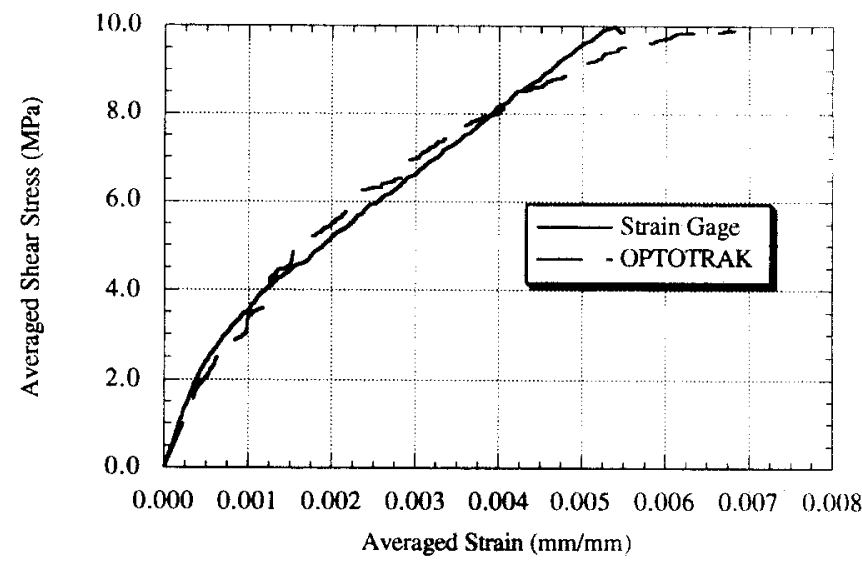

FIGURE 10. Shear stress-strain curve obtained from strain gauge and OPTOTRAK for DRECC.

sion-compression strength of the material using the fact that a state of pure shear exists at the center of the specimen. Since the maximum shear stress occurs at the middle of the specimen and is one and a half times the average shear stress over the beam height (see Figure 3), the biaxial tension-compression strength can be plotted against the uniaxial tensile strength for the four different material systems as shown in Figure 11. The biaxial tension-compression strength for the ECC appears higher than the uniaxial tensile strength, although there seems to be a slight increase even in the case of PC. Recognizing the simplifying assumptions such as the theoretical maximum of the shear stress distribution being 1.5 times the average value and the variability in the direct tension test results of $P C$, this increase is negligible compared to the significant biaxial effect observed in the case of the ECCs. Surprisingly, this biaxial effect is also found to be negligible in

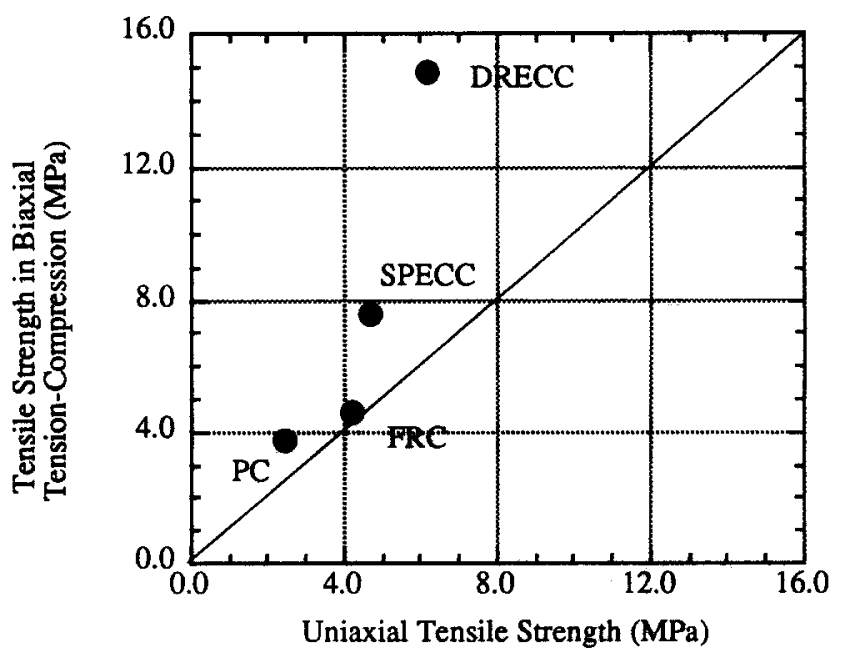

FIGURE 11. The biaxial effect on the various materials tested. 
the case of the conventional FRC. The test results are too preliminary to develop a theory for the biaxial tension-compression behavior on ECCs. More carefully controlled direct biaxial experiments are underway at the University of Michigan to confirm this observation.

\section{Conclusions}

A preliminary experimental investigation of the shear behavior of a special class of cementitious composites (termed ECC) is presented in this article. Our results indicate that the shear responses of the PC, FRC, and ECCs mirror the tensile properties of the corresponding cementitious materials. However, the ultimate strength and strain in tension and in shear are not identical, since the deformation pattern in the shear panel is not uniform. This was confirmed by visual inspection of the cracking pattern [18]. For the ECCs, these differences may also be influenced by the biaxial tension-compression stress state rather than uniaxial tension in the shear beams. In addition, the shear response does not appear to reflect the fracture toughness of the materials, particularly that of the SPECC, which has the highest fracture energy of all the materials tested here. However, this should be expected since the shear panel size is small in comparison to the fracture process zone measured in the SPECC fracture specimen which covers an area of $1150 \mathrm{~cm}^{2}$ [2]. In a full-scale structure much larger than the shear panel tested in this program, the high fracture energy of SPECC may govern the shear strength of the structure.

The shear strength and strain capacity of ECC materials were shown to be superior compared to ordinary concrete and FRC materials. It was also observed that the cracking behavior in terms of crack widths is better in the case of ECC material. In particular, it is noted that after first crack, ECCs allow continued straining with an increase in load capacity, whereas FRC and the PC exhibit rapid load drop. Although the RC system shows macroscopically comparatively good strength and ductility, much of the straining and loadbearing capacity after first crack are born by the wire mesh, plastically deforming in a single opening large crack in the concrete.

The tensile and shear stress-strain curves and the multiple cracking pattern revealed in the ECC specimen represent evidence that the pseudo strainhardening tensile properties of ECC materials can be successfully translated into advantageous structural shear response. The good strength and ductility of ECCs accompanied with distributed small cracks of widths of around $0.1 \mathrm{~mm}$ suggest that ECCs can be exploited in applications where mechanical perfor- mance and structural durability are of major importance.

\section{Acknowledgments}

The work reported here represents preliminary test results based on a research project sponsored by the Shimizu Corporation through a research contract to the University of Michigan, Ann Arbor. Special acknowledgment is made to Dr. T. Fujimori for his tireless efforts in bringing about the research partnership between Shimizu Corporation and the University of Michigan. Additional input to this research program by Dr. Y. Kaneko is also gratefully acknowledged.

\section{References}

1. Li, V.C.; Wu, H.C., Journal of Applied Mechanics Reviews 1992, 45, 8 390-398.

2. Li, V.C.; Hashida, T. Journal of Materials Science Letters 1993, 12, 898-901.

3. Li, V.C.; Leung, C.K.Y. ASCE J of Eng. Mech. 1992, 118, 2246-2264.

4. Csagoly, P.F. Report of the Ontario Ministry of Transportation and Communications, 1979.

5. Nguyen, N.T. M.Sc. Thesis, The Massachusetts Institute of Technology, Cambridge, MA, 1988.

6. Eligehausen, R.; Sawade G. In Fracture Mechanics of Concrete Structures; Elfgren, L., Ed.; Chapman \& Hall: New York, 1989; pp 281-299.

7. Lamberson, E.A.; Barker, J.M. Concrete International 1981, August, 93-101.

8. Batson, G.; Jenkins, E.; Spatney, R. ACI Journal 1972, 69, 640-644.

9. Williamson, G.R. Proceedings, U.S. Army Science Conference 1978, 3, 363-377.

10. Sharma, A.K. ACI Journal Proceedings 1986, 83, 624-628.

11. Narayanan, R.; Darwish, I.Y.S. ACI Structural Journal Proceedings 1987, 84, 216-227.

12. Swamy, R.N.; Bahia, H.M. Concrete International 1985, March, 35-40.

13. Li, V.C.; Ward, R.; Hamza, A.M. ACI Journal of Materials 1992, 89, 499-508.

14. Fritz, C.; Reinhardt, H.W. In High Performance Fiber Reinforced Cement Composites; Reinhardt, H.W.; Naaman, A.E., Eds.; Chapman \& Hall, 1992; pp 213-225.

15. VanMier, J.G.M.; Timmers, G. In High Performance Fiber Reinforced Cement Composites; Reinhardt, H.W.; Naaman, A.E., Eds.; Chapman \& Hall, U.K. 1992; pp 348-360.

16. Wang, M.L.; Maji, A.K. In High Performance Fiber Reinforced Cement Composites; Reinhardt, H.W.; Naaman, A.E., Eds.; Chapman \& Hall, 1992; pp 203-212.

17. Li, V.C. In Proceedings of the 4th RILEM International Symposium on Fiber Reinforced Cement and Concrete; Swamy, R.N., Ed.; E \& FN Spon, U.K., 1992; pp 12-30.

18. Arakawa, T.; Ono, K. Transactions of the Architectural Institute of Japan 1957, 57, 581-584 (in Japanese).

19. Li, V.C.; Mishra, D.K.; Wu, H.C. UMCEE Report No. 92-33; University of Michigan: Ann Arbor, 1992.

20. Li, V.C.; Wu, H.C.; Mishra, D.K.; Maalej, M.; Hashida, T.; submitted to Journal of American Ceramic Society 1993.

21. Kupfer, H.; Hilsdorf, H.K.; Rusch, H. ACI Journal Proceedings 1969, 66, 656-666. 